\title{
Free Thyroid Hormone Concentrations during Postnatal Development in the Rat
}

\author{
P. WALKER, J. D. DUBOIS, AND J. H. DUSSAULT ${ }^{(20)}$ \\ Laboratoires de Recherches en Endocrinologie et Metabolisme, Le Centre Hospitalier de l'Universite Laval, Quebec \\ GIV 4G2 Canada
}

\begin{abstract}
Summary
Sprague-Dawley rats were sacrificed by decapitation at $5,7,12$, $14,22,26,32$, and 40 days of age. Adult animals (175 to $225 \mathrm{~g}$ ) were also studied. Serum-free thyroxine (FT4) concentrations rose rapidly between 5 and 12 days to levels similar to adult concentrations, whereas the percentage of FT4 was relatively high between 5 and 12 days before declining to adult values by 14 days. Serumfree triiodothyronine (FT3) concentrations rose progressively to attain peak concentrations at $\mathbf{2 6}$ days and subsequently declined to adult levels by 40 days. The percentage FT3 rose in parallel with the FT3 concentrations to peak values at 22 to 26 days before declining to adult levels. FT4/thyroid-stimulating hormone (TSH) and FT3/TSH ratios increased progressively through 22 days of age in parallel with the FT3/FT4 ratio. These data indicate that free thyroid hormone concentrations follow essentially the same developmental profile as do total thyroid hormone concentrations. Progressive maturation of the negative feedback control mechanism for the pituitary-thyroid axis, as assessed by the FT4/TSH and FT3/TSH ratios, occurs through 14 days. However, the continued rise in FT3 concentrations, FT3/TSH, and FT3/FT4 ratios through 26 days suggests a further resetting of the setpoint of the pituitary-thyroid axis possibly related to the stress of weaning.
\end{abstract}

\section{Speculation}

Maturation of the pituitary-thyroid axis in the rat is principally a postnatal phenomenon. Careful study of the developmental profile of this axis under physiologic and pathologic states may afford considerable insight into the ontogenesis of the pituitarythyroid axis in the human fetus.

The hypothalamo-pituitary-thyroid axis develops during the neonatal period in the rat (6). A recent report from this laboratory has documented the ontogenetic pattern of thyroxine (T4) and triiodothyronine (T3) kinetics from birth to adulthood in this species (4). This study indicated that although T4 concentrations achieve adult levels by 12 days, there is a delay of approximately 12 days before peak circulating T3 concentrations are achieved. Although data are available for the ontogenesis of circulating free thryoid hormone concentrations in the human $(7,10,11,14)$ and ovine fetus $(5,9)$, little is known of the maturational processes by which negative feedback control of the pituitary-thyroid axis is controlled. Because free thyroid hormone concentrations in serum reflect more adequately the availability of active hormones at the tissue level, we undertook a study of the free concentrations of both $\mathrm{T} 4$ and $\mathrm{T} 3$ in the rat during postnatal development.

\section{MATERIALS AND METHODS}

Virgin Sprague-Dawley rats were mated at the supply house (Canadian Breeding Farms, St. Constant, Laprairie, Canada) and shipped 14 to 16 days later. Pregnant animals were housed in separate cages with free access to rat laboratory chow and water in a controlled (14 hr light) room. Humidity was not controlled.

Animals were sacrificed by decapitation between 9:00 and 11:00 a.m. at 5, 7, 12, 14, 22, 26, 32, and 40 days of age. Adult animals ( 175 to $225 \mathrm{~g}$ ) were also studied. Each group comprised 6 to 12 studies using both sexes distributed randomly. For the two youngest age groups, blood was pooled from several animals to yield a sufficient volume of serum. The serum harvested was stored at $-20^{\circ} \mathrm{C}$ pending analysis.

Serum $\mathrm{T} 4$ and $\mathrm{T} 3$ concentrations were measured by specific double antibody radioimmunoassay $(1,2)$. Serum-free T4 (FT4) and T3 (FT3) concentrations were measured using the Sephadex binding method described by Irvine (15). Serum TSH concentrations were determined using the rat TSH assay kit kindly provided by the Rat Pituitary Hormone Distribution Program of the National Institute of Arthritis, Metabolism, and Digestive Diseases (reference standard rat-TSH-RP-3; NIAMD-anti-rat TSH serum3).

\section{RESULTS}

Table 1 illustrates the serum TSH, T4, and T3 concentrations with increasing age in the rat. Serum T4 concentrations are low at 5 days of age and rise rapidly to achieve relatively stable adult values by 14 days. Serum T3 concentrations are also low at 5 days and rise to peak values at 26 days, although values comparable to those of the adult are observed at 22 days. Serum TSH concentrations also rise rapidly to peak levels at 12 days followed by a decline toward adult concentrations between 14 and 22 days.

Serum FT4 concentrations (Table 2) rise progressively to attain peak concentrations of $288.01 \pm 12.07 \mathrm{pg} / \mathrm{dl}$ at 26 days. Thereafter, there is a rapid decline at 32 days $(171.52 \pm 5.55 \mathrm{pg} / \mathrm{dl})$ before adult levels are attained at 40 days $(206.45 \pm 5.23 \mathrm{pg} / \mathrm{dl})$. The percentage of FT3, however, rises progressively to attain peak values at 22 days followed by a progressive decline to adult levels (Table 3). Adult values are not significantly different from those observed in the youngest animals studied.

The ratios of FT4 and FT3 to serum TSH concentrations are depicted in Figure 1. Both ratios increase progressively through 22 days of age. At 26 days, however, the FT3/TSH ratio significantly exceeds that of the FT4/TSH ratio. Subsequently, the ratios again appear to change in parallel.

FT3/FT4 ratios with increasing age are illustrated in Figure 2. Mean FT3/FT4 ratios increase from $0.021 \pm 0.002$ at 5 days to peak values of $0.163 \pm 0.009$ at 26 days followed by a decline to adult levels of $0.100 \pm 0.008$.

\section{DISCUSSION}

The rat is born in an immature state shortly after completion of enbryogenesis of the hypothalamus, pituitary, and thyroid (3, 8, 12). Progressive anatomical and functional maturation proceeds during the first two weeks of postnatal life $(3,6,8)$. We have 
Table 1. Serum TSH, T4, and T3 concentrations during postnatal development in the rat

\begin{tabular}{crccr}
\hline $\begin{array}{c}\text { Age } \\
\text { (days) }\end{array}$ & $N$ & $\begin{array}{c}\text { TSH } \\
(\mathrm{ng} / \mathrm{ml})\end{array}$ & $\begin{array}{c}\text { T4 } \\
(\mu \mathrm{g} / \mathrm{dl})\end{array}$ & \multicolumn{1}{c}{$\begin{array}{c}\mathrm{T} 3 \\
(\mathrm{ng} / \mathrm{dl})\end{array}$} \\
\hline 5 & 6 & $359.0 \pm 21.9^{1}$ & $1.66 \pm 0.17$ & $7.03 \pm 2.38$ \\
7 & 12 & $551.8 \pm 53.7$ & $2.06 \pm 0.13$ & $17.92 \pm 0.42$ \\
12 & 11 & $706.4 \pm 69.1$ & $3.71 \pm 0.21$ & $54.91 \pm 1.64$ \\
14 & 9 & $565.4 \pm 60.7$ & $5.67 \pm 0.25$ & $54.95 \pm 1.36$ \\
22 & 7 & $405.8 \pm 28.3$ & $4.21 \pm 0.17$ & $89.25 \pm 4.70$ \\
26 & 9 & $374.7 \pm 31.4$ & $4.82 \pm 0.19$ & $100.70 \pm 3.78$ \\
32 & 6 & $439.1 \pm 39.9$ & $5.00 \pm 0.20$ & $63.29 \pm 3.54$ \\
40 & 7 & $229.1 \pm 40.7$ & $4.58 \pm 0.20$ & $82.91 \pm 3.30$ \\
Adult & 7 & $464.6 \pm 49.1$ & $5.53 \pm 0.50$ & $89.48 \pm 4.63$ \\
\hline
\end{tabular}

${ }^{1}$ Mean \pm S.E.

Table 2. Serum FT4 concentrations with increasing age in the rat

\begin{tabular}{crccc}
\hline $\begin{array}{c}\text { Age } \\
(\text { days })\end{array}$ & $N$ & $\begin{array}{c}\text { T4 } \\
(\mu \mathrm{g} / \mathrm{dl})\end{array}$ & \% FT4 & $\begin{array}{c}\text { FT4 } \\
(\mathrm{ng} / \mathrm{ml})\end{array}$ \\
\hline 5 & 6 & $1.66 \pm 0.17^{1}$ & $0.057 \pm 0.004$ & $0.946 \pm 0.066$ \\
7 & 12 & $2.06 \pm 0.13$ & $0.062 \pm 0.004$ & $1.277 \pm 0.082$ \\
12 & 11 & $3.71 \pm 0.21$ & $0.065 \pm 0.004$ & $2.412 \pm 0.148$ \\
14 & 9 & $5.67 \pm 0.25$ & $0.045 \pm 0.002$ & $2.552 \pm 0.113$ \\
22 & 7 & $4.12 \pm 0.17$ & $0.061 \pm 0.003$ & $2.568 \pm 0.126$ \\
26 & 9 & $4.82 \pm 0.19$ & $0.046 \pm 0.003$ & $2.217 \pm 0.145$ \\
32 & 6 & $5.00 \pm 0.20$ & $0.056 \pm 0.004$ & $2.800 \pm 0.200$ \\
40 & 7 & $4.58 \pm 0.20$ & $0.039 \pm 0.001$ & $1.786 \pm 0.046$ \\
Adult & 7 & $5.53 \pm 0.40$ & $0.040 \pm 0.001$ & $2.212 \pm 0.055$ \\
\hline
\end{tabular}

' Mean \pm S.E.

Table 3. Serum FT3 concentrations

\begin{tabular}{crccc}
\hline $\begin{array}{c}\text { Age } \\
\text { (days) }\end{array}$ & $\boldsymbol{N}$ & $\begin{array}{c}\text { T3 } \\
\text { (ng/dl) }\end{array}$ & \% FT3 & $\begin{array}{c}\text { FT3 } \\
(\mathrm{pg} / \mathrm{dl})\end{array}$ \\
\hline 5 & 6 & $7.03 \pm 2.38^{1}$ & $0.221 \pm 0.006$ & $15.54 \pm 0.64$ \\
7 & 12 & $17.92 \pm 0.42$ & $0.221 \pm 0.005$ & $34.60 \pm 0.92$ \\
12 & 11 & $54.91 \pm 1.64$ & $0.283 \pm 0.004$ & $155.40 \pm 2.44$ \\
14 & 9 & $54.95 \pm 1.36$ & $0.276 \pm 0.007$ & $151.66 \pm 4.71$ \\
22 & 7 & $89.25 \pm 4.70$ & $0.304 \pm 0.007$ & $271.32 \pm 8.25$ \\
26 & 9 & $100.70 \pm 3.78$ & $0.286 \pm 0.001$ & $288.01 \pm 12.07$ \\
32 & 6 & $63.29 \pm 3.54$ & $0.271 \pm 0.006$ & $171.52 \pm 5.55$ \\
40 & 7 & $82.91 \pm 3.30$ & $0.249 \pm 0.006$ & $206.45 \pm 5.23$ \\
Adult & 7 & $89.48 \pm 4.63$ & $0.233 \pm 0.010$ & $208.49 \pm 8.55$ \\
\hline
\end{tabular}

${ }^{1}$ Mean \pm S.E.

previously shown that the progressive increases in serum T4 and T3 concentrations after birth are principally the result of increasing production, although no estimation of the relative contribution of peripheral as opposed to thyroidal T3 production could be assessed (4). The present study confirms the postnatal dynamics for serum TSH, T4, and T3 concentrations and indicates that free thryoid hormone concentrations follow essentially the same developmental profile as do total thyroid hormone concentrations. FT4 concentrations achieve relatively stable adult levels by 12 to 14 days whereas there is a delay of 12 days before peak FT3 concentrations are attained. However, the rates of increase of the free thyroid hormone concentrations are similar through 14 days as are the FT4/TSH and FT3/TSH ratios, suggesting progressive maturation of the negative feedback control mechanism for the pituitary-thyroid axis.

Thyroidal TSH responsiveness during the neonatal period in the rat has not been systematically examined, although it has been suggested the thyroid is relatively unresponsive to TSH stimulation during the first few days of life (17). The low FT4, FT3, FT4/ TSH, and FT3/TSH values observed at 5 days may therefore suggest a relative state of hypothyroidism in the newborn rat. In support of this possibility is the observation that pituitary TSH

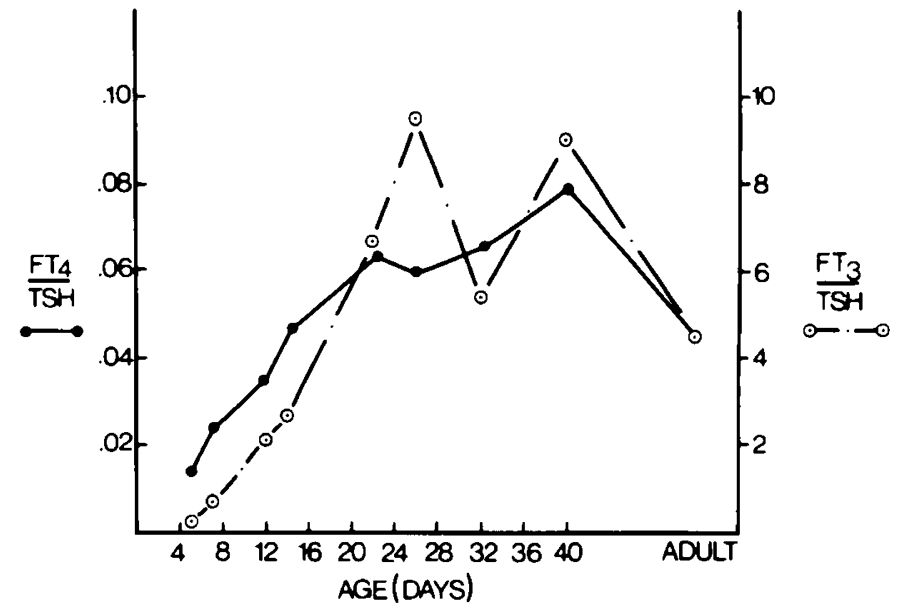

Fig. I. FT4/TSH $(O)$ and FT3/TSH $(\odot)$ ratios with increasing age in the rat.

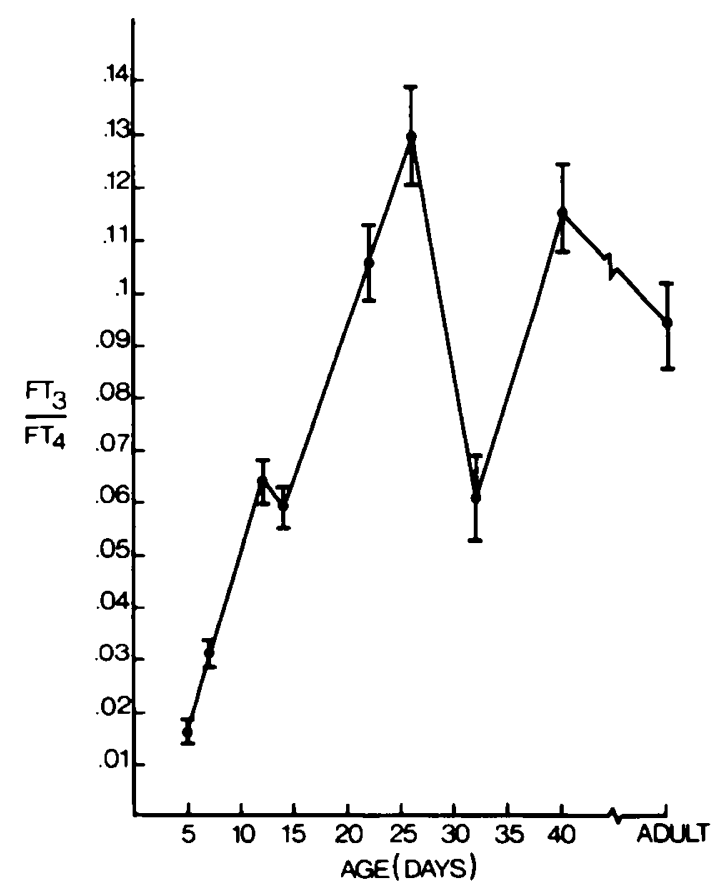

Fig. 2. Developmental profile of FT3/FT4 ratios in the rat.

responsiveness to thyrotropin-releasing hormone is increased at this age compared to adults (19).

Vigouroux (18) has shown that thyroidal iodine content increases rapidly from birth to 20 days. These observations are supported by progressively increasing thyroidal deiodinase activity (16), an enzyme which is known to be TSH responsive, to maximum values at 18 days. The FT3/FT 4 ratios observed herein in the presence of progressively increasing FT4/TSH and FT3/TSH ratios during this time support the possibility of increasing thyroidal responsiveness to $\mathrm{TSH}$, although the relative contribution to circulating $\mathrm{T} 3$ concentrations of peripheral $\mathrm{T} 4$ monodeiodination to $T 3$ cannot be evaluated.

Of interest is the continued rise in the FT3 concentration and FT3/TSH and FT3/FT4 ratios through to 26 days suggesting augmented tissue requirements of $T 3$, during the period of weaning ( 21 to 25 days in our animals). Thyroidal accumulation of radioiodide has been shown to be markedly elevated at this time (13). The absence of a significant decline in serum T4 and FT4 concentrations at this time may suggest augmented thyroidal secretion of $\mathrm{T} 3$ as the predominant factor. Furthermore, the 
pituitary appears to be relatively insensitive to the feedback effects of T3 at this time (19), suggesting the possibility of a further resetting of the setpoint of the hypothalamo-pituitary-thyroid axis in relation to the additional stress of weaning.

In sum, the progressive increases in serum FT4 and FT3 concentrations during the first 4 weeks of postnatal life in the rat suggests increasing thyroidal responsiveness presumably due to TSH stimulation. The increasing FT4/TSH and FT3/TSH ratios during this time reflect a progressive maturation of the negative feedback control mechanism of the pituitary-thyroid axis.

\section{REFERENCES AND NOTES}

1. Chopra, I. J.: A rapid radioimmunoassay for measurement of thyroxine in unextracted serum. J. Clin. Endocrinol. Metab., 34: 938 (1972).

2. Chopra, I. J., Ho, R. S., and Lam, R. W.: An improved radioimmunoassay of triiodothyronine in serum: its application to clinical and physiological studies. J. Lab. Clin. Med., 80: 729 (1972).

3. Daikoku, S., Kotsu, T., and Hashimoto, M.: Electron microscopic observations on the development of the median eminence in perinatal rats. $Z$. Anat Entwicklungsgesch., 134: 311 (1971).

4. Dubois, J. D., and Dussault, J. H.: Ontogenesis of thyroid function in the neonatal rat. Thyroxine (T4) and triiodothyronine (T3) production rates. Endocrinology. 101: 435 (1977)

5. Dussault, J. H., and Fisher, D. A.: Thyroxine et triiodothyronine libres chez la brebis et son foetus. Union Med. Can., 101: 689 (1972).

6. Dussault, J. H., and Labrie, F.: Development of the hypothalamic-pituitarythyroid axis in the neonatal rat. Endocrinology, 97: 1321 (1975).

7. Erenberg, A., Phelps, D. L., Lam. R., and Fisher, D. A.: Total and free thyroid hormone concentrations in the neonatal period. Pediatrics, 53: 211 (1974).

8. Fink, G., and Smith, G. C.: Ultrastructural features of the developing hypothalamo-hypophysial axis in the rat: correlative study. Z. Zellforsch Mikrosk. Anat., 119: 208 (197.1).

Copyright $\odot 1980$ International Pediatric Research Foundation, Inc $0031-3998 / 80 / 1403-0247 \$ 02.00 / 0$
9. Fisher, D. A., Dussault, J. H., Erenberg, A., and Lam, R. W.: Thyroxine and triiodothyronine metabolism in maternal and fetal sheep. Pediatr. Res., 6: 894 (1972).

10. Fisher, D. A., Hobel, C. J., Garza, R., and Pierce, C. A.: Thyroid function in the preterm fetus. Pediatrics, 46: 208 (1970).

11. Fisher, D. A., Odell, W. D., Hobel, C. J., and Garza, R.: Thyroid function in the term fetus. Pediatrics, 44: 526 (1969).

12. Geloso, J. P., Hemon, P., Legrand, J., Legrand, C., and Jost, A.: Some aspects of thyroid physiology during the perinatal period. Gen. Comp. Endocrinol., 10 191 (1968).

13. Goldman, M., and Bauer, S. R.: A comparative study of iodine uptake by thyroid and thymus gland of male and female Sprague-Dawley rats of different ages. Acta Endocrinol., 85: 64 (1970).

14. Greenberg, A. H., Czerinichow, P., Reba, R. C., Tyron, J., and Blizzard, R. M. Observations on the maturation of thyroid function in early fetal life. J. Clin. Invest., 49: 1790 (1970).

15. Irvine, C. H. G.: Measurement of free thyroxine in human serum by a Sephadex binding method. J. Clin. Endocrinol. Metab., 38: 655 (1974).

16. Knoff, J., and Fäberová, A.: Ontogenetic development of deiodinase and aminotransaminase in rat thyroid gland. Biol. Neonate, 28: 282 (1976).

17. Kojima, A., and Hershman, J. M.: Effect of thyrotropin-releasing-hormone (TRH) in maternal, fetal and newborn rats. Endocrinology, 94: 1133 (1974).

18. Vigouroux, E.: Dynamic study of postnatal thyroid function in the rat. Acta Endocrinol. (Kbh), 83: 752 (1976).

19. Walker, P., Verret, G., Coulombe, P., and Dussault, J. H.: Effects of triiodothyronine (T3) on the thyrotropin-releasing hormone (TRH) induced thyrotropin (TSH) release in the neonatal rat. 54th Meeting, American Thyroid Association (Abstract) T-15, 1978.

20. Requests for reprints should be addressed to: Jean H. Dussault, M.D. M.Sc. F.R.C.P. (C), Laboratoires de Recherches en Endocrinologie et Metabolisme. Le Centre Hospitalier de l'Université Laval, 2705, boul. Laurier, Québec GIV 4G2, CANADA

21. This research was supported in part by a grant no. MA-5730 from the Medical Research Council of Canada.

22. Received for publication November 29, 1978.

23. Accepted for publication April 17, 1979 